\title{
Adherence to TB treatment remains low during continuation phase among adult patients in Northwest Ethiopia
}

\author{
Kassahun Dessie Gashu ${ }^{*^{*}}$ D, Kassahun Alemu Gelaye ${ }^{2}$ and Binyam Tilahun ${ }^{1}$
}

\begin{abstract}
Background: Patients' failure to adhere to TB treatment was a major challenge that leads to poor treatment outcomes. In Ethiopia, TB treatment success was low as compared with the global threshold. Despite various studies done in TB treatment adherence, little was known specifically in continuation phase where TB treatment is mainly patient-centered. This study aimed to determine adherence to TB treatment and its determinants among adult patients during continuation phase.

Methods: We deployed a facility-based cross-sectional study design supplemented with qualitative data to explore perspectives of focal healthcare providers. The study population was all adult ( $\geq 18$ years) TB patients enrolled in the continuation phase and focal healthcare workers in TB clinics. The study included 307 TB patients from 22 health facilities and nine TB focal healthcare providers purposively selected as key-informant. A short (11 questions) version Adherence to Refill and Medication Scale (ARMS) was used for measuring adherence. Data was collected using an interviewer-administered questionnaire and in-depth interview for qualitative data. Binary logistic regression was applied to identify factors associated with patient adherence. We followed a thematic analysis for the qualitative data. The audio data was transcribed, coded and categorized into themes using OpenCode software.
\end{abstract}

Results: Among 307 participants, 64.2\% (95\% Cl (58.6-69.4\%) were adherent to TB treatment during continuation phase. A multi-variable analysis shown that secondary education ( $\mathrm{AOR}=4.138,95 \% \mathrm{Cl}$; 1.594-10.74); good providerpatient relationship ( $\mathrm{AOR}=1.863,95 \% \mathrm{Cl} ; 1.014-3.423)$; good knowledge on $\mathrm{TB}$ treatment $(\mathrm{AOR}=1.845,95 \% \mathrm{Cl}$; $1.012-3.362)$ and middle family wealth ( $A O R=2.646,95 \% \mathrm{Cl} ; 1.360-5.148)$ were significantly associated with adherence to TB treatment. The majority (58\%) of patients mentioned forgetfulness, and followed by $17.3 \%$ of them traveling away from home without pills as major reasons for non-adherence to TB treatment.

Conclusions: The study indicated that patients' adherence to TB treatment remains low during continuation phase. The patient's education level, knowledge, family wealth, and provider-patient relationship were found positively associated with patient adherence. Forgetfulness, traveling away, and feeling sick were major reasons for nonadherence to TB treatment. Interventional studies are needed on those factors to improve patient adherence to TB treatment during continuation phase.

Keywords: Adherence, Continuation phase, Tuberculosis, Ethiopia

\footnotetext{
* Correspondence: kassahundessie@gmail.com

${ }^{1}$ Department of Health Informatics, Institute of Public Health, College of Medicine and Health Sciences, University of Gondar, Gondar, Ethiopia

Full list of author information is available at the end of the article
} 


\section{Background}

TB treatment follows a Directly Observed Treatment, Short-course (DOTS) strategy with a combined course of antibiotics that include rifampicin $(\mathrm{R})$, isoniazid $(\mathrm{H})$, pyrazinamide $(\mathrm{Z})$ and ethambutol $(\mathrm{E})$ for 2 months of intensive phase followed by $4 \mathrm{H}+4 \mathrm{R}$ for 4 months continuation phase [1-3]. During intensive phase, daily medication is expected to be delivered under healthcare provider's observation. While, during continuation phase daily medication is supposed to be supported by community including family, relatives, neighbors and community health workers [4-6].

Stop TB Strategy focuses on universal access to patient-centered treatment and high-quality care and treatment support as the cornerstone of DOTS to improve treatment success rate [3]. Adherence to TB treatment is a regular and complete medication intake that gives individual TB patients the best chance of cure and also protects the community from the spread of TB [3]. Patients' failure to adhere to TB treatment has been a global problem that results in poor treatment outcomes like, drug resistance, relapse, death, and increased health care costs $[4,7,8]$. In Ethiopia, recent evidences indicated the national pooled TB treatment success rate was low as compared with the global threshold [9-11]. The low treatment success rate was prevailing in Northern part of Ethiopia [11].

Non-adherence to TB treatment has been reported as a major challenge in Ethiopia [12-17]. Forgetfulness [12, $16,18,19]$; poor provider-patient relationship as well as communication [19-21], poor knowledge towards TB treatment, distance to the health facility, adverse clinical experiences and alcohol intake [14, 18, 19, 22-25] were most commonly reported reasons for non-adherence to TB treatment. All the previous studies, however, pooled level of adherence from both intensive and continuation phase, where the treatment approach for intensive and continuation phases were quite different. In addition, most studies tried to assess TB treatment adherence from the patient's perspectives, while healthcare providers' perspectives have gotten little attention. Pill count has been predominantly used for measuring adherence by many studies, despite, its proven limitation of overestimating the level of patient adherence to TB treatment [26].

Some studies tried to analyze the treatment phase as a predictor variable for patient adherence to TB treatment and found that continuation phase was a risk factor for non-adherence $[18,19,27]$. That may indicated that non-adherence could be more common during the continuation phase of treatment. A recent finding in the study area also showed that adherence to TB treatment was $84 \%(183 / 218)$ in intensive and 66\% (58/88) during continuation phases [19].
The strategies for the TB treatment adherence support were quite different during intensive and continuation phases. During the intensive phase, patients attend the nearby clinic every morning to swallow their pills under direct observation of healthcare providers that could motivate and enforce patients to adhere in their medication. Whereas, a continuation TB treatment phase is a self-managed (patient-centered) approach in which TB pills are daily taken by the patient at home with a weekly pill refilling schedule from the nearby health facility. So that during continuation phase patients could be reluctant to take pills at home and community-based treatment supporters may be busy in own competing business. The national TB treatment guideline suggests assigning treatment supporters including, family, health extension workers for each patient to support the treatment follow-up [27]. However, little is known about the challenges of community-based treatment support systems during the continuation phase. Above all, evidence was limited on factors affecting adherence to TB treatment during continuation phase.

Therefore, this study aimed to determine level of adherence and associated factors among adult TB patients enrolled in the continuation phase. It also aimed to explore TB focal person's perceptions of patient adherence to $\mathrm{TB}$ treatment during the continuation treatment phase.

\section{Methods \\ Study design}

An Institutional based cross-sectional study was conducted with adult TB patients in the continuation treatment phase from March 9 to May 30, 2019. It was supplemented with qualitative data to explore the lived experiences and perspectives of the healthcare providers on patient adherence during the continuation phase.

\section{Study setting and participants}

The study was conducted in 9 districts of Central Gondar Zone and Gondar town administration in Northwestern Ethiopia. Namely, Gondar Zuria, Tach Armachio, Wegera, East Dembia, West Belesa, Takusa, East Belesa, Alefa, and Gondar town administration were included in the study. The study area consists of 74 functional public health facilities (Health centers and Hospitals) serving approximately 2.9 million people in the area. Primary healthcare units that involves Health posts, Health Centers and district hospitals are mandated to provide TB treatment and care. In each health facility, a TB clinic has been established with at least one TB focal healthcare provider to regularly manage cases and follow their treatment. TB focal healthcare provider is a healthcare provider that received additional short- 
term training on $\mathrm{TB}$ and permanently assigned to $\mathrm{TB}$ Clinic.

The study population included all adult ( $\geq 18$ years) TB patients enrolled in the continuation treatment phase as eligible participants. Patients with Multi-drug-resistant Tuberculosis (MDR-TB) and Extensively Drug-resistant Tuberculosis (XDR-TB) were not included in the study due to the distinct treatment period and approaches. All healthcare providers who were assigned as TB focal person in TB clinics were eligible for the key-informant interview.

\section{Sample size and sampling techniques}

We calculated the sample size using a single population proportion formula with assumptions, including, proportion of patients adherent to TB medications $(P=66 \%)$ during the continuation phase [19]; margin of error $(d=$ $5 \%$ ), and 1.5 design effect. Considering the finite population and $10 \%$ non-response rate, the final sample size was $331 \mathrm{~TB}$ patients selected from 22 health facilities in the 9 districts. Facilities were randomly selected stratifying by urban (town administrations) and rural settings. All eligible TB patients were included during the study period. Nine TB focal healthcare providers were purposively selected for key-informant interview from nine different health facilities.

\section{Data collection tools and procedures}

1) Description of interviewer-administered questionnaire and key-informant interviews

In this study, socio-demographic characteristics, disease characteristics, TB treatment-related knowledge, and attitude, provider-patient relationship using below and above the average score as a cut-off values. Family wealth quantiles were also included as predictor variables. We used an interviewer-administered questionnaire for socio-demographic, behavioral, and treatment adherence related data using Amharic (local language). But the treatment related information was taken from TB unit registers. The internal consistency of the tool was checked through piloting, hence, the Cronbach's $\alpha$ value found to be 0.769 , which was approaching well with the cut of value [28]. The content and face validity were also evaluated by six senior domain experts selected from TB treatment centers, TB experts in health offices, and behavioral researchers in research and teaching institutes. We trained and employed six data collectors and two supervisors. We assessed patients' TB treatment-related knowledge using 8 questions that include, TB curability, how to confirm cure of the disease, TB treatment period, refilling time and adherence, feeding practice, side-effects, and treatment supporter's role.
Those patients who scored above the median value were determined as good knowledge [17, 19, 29, 30]. Similarly, a 4 attitude questions that include, patient trust on $\mathrm{TB}$ medication, medication related misconceptions, value for medication and belief of cure were used to assess attitude towards TB treatment $[19,20]$. Those patients who score above the median value of attitude questions were determined as good attitude towards TB treatment. In order to measure provider-patient relationship, we used a 6 questions that include ways of communication, [19] were adapted from literatures. The family wealth quantiles (lowest, second, middle, fourth, highest) was constructed from multiple items including household assets, services, and facilities [31]. Then for simplicity of analysis, we merged into three outcomes (poor, middle and rich) by categorizing below middle quantiles into poor, middle quantiles as it is and above the middle quantiles into rich.

For the qualitative data, a semi-structured key informant interview guide was used to explore the existing provider-patient relationship and support during the continuation treatment phase. Participants were asked mainly about their opinion on which $\mathrm{TB}$ treatment phase is the risk for non-adherence? Why nonadherence to TB treatment was high on the specified phase? How was the communication and relationship between patients and healthcare providers? And how effective was the community-based treatment support system? The key-informant interview was recorder for audio after getting consent from each participants.

\section{2) Description of assessment of the outcome}

To assess adherence to TB treatment during continuation phase we deployed a short (11 questions) version of the Adherence to Refill and Medication Scale (ARMS) [32]. The original ARMS tool consists of 12 questions with two subscales, 8 questions about medication-taking, and 4 questions about refilling [33]. One of the items, "How often do you forget to take your medicine when you are supposed to take it more than once a day?" was not relevant to TB medication, since TB pills often are taken once a day. Each of the items were structured as a Likert scale with responses of "none," "some," "most," or "all" of the time, which were given values from 1 to 4 .

\section{Data analysis}

We used a Principal Component Analysis (PCA) technique to compute the family wealth index quantile separately for urban and rural depending on assets and services specific to the urban and rural population [31].

Adherence to TB treatment was measured using the short (11 questions) version ARMS values that range from $1=$ "none of the time" to $4=$ "all of the time". One 
item was reverse coded then the overall adherence score ranges from 11 to 44 . The lower scores indicate better adherence and the higher score represents a higher level of non-adherence, items were asking about how frequently failed to adhere to specific elements [33]. The scales were further transformed into dichotomous outcomes using the recommended classification (scored 11 as adhered and $>11$ as non-adhered) [32, 33].

We used the Variance Inflation Factor (VIF) to check the multicollinearity effect among predictor variables [34]. We conducted a single-level analysis using binary logistic regression to identify factors that are associated with adherence to $\mathrm{TB}$ treatment during the continuation phase. The Crude Odds Ratio (COR) and Adjusted Odds Ratio (AOR) with $95 \% \mathrm{CI}$ and $p$ value $<0.05$ were computed using STATA version 14 software to determine statistical significance of the association between predictor and outcome variables.

For the qualitative data analysis, we transcribed the audio data into the Amharic language by experts in the field and translated into English by fluent speakers. After familiarization with the transcript, we assigned codes inductively and deductively and categorized into themes. We examine patterns, relationships, contradictory responses, and gaps in understanding in each theme. Quotes were selected and presented for norms of the participants' shared perceptions.

\section{Results}

\section{Socio-demographic and economic characteristics of participants}

In this study, a total of 307 participants (92\% response rate) were interviewed. More than half of the participants 178 (58.0\%) were males. Of the total participants, 110 (35.8\%) were aged between 35 and 44 years. The median age of the participants was 29.0 years with a minimum of 18 and a maximum of 84 years. Regarding marital status, 142 (46.3\%) of the participants were single. The majority, 285 (92.8\%) of them were Orthodox Christian followers. Of the total participants, 220 (71.7\%) were urban residents. Among the participants, $101(32.9 \%)$ could not read and write. The family asset evaluation shown that $62(20.2 \%)$ were in lowest quantile. One hundred twenty two (39.7\%) of the participants did not have a mobile phone at all (Table 1).

Of the nine key-informants, seven were selected from Health Centers and two from Hospitals. Six were males. The age of the participants ranged from 26 to 40 years. Only three of the participants had a first degree and above. Working experience ranged from 6 months to 7 years in TB clinic.

\section{Adherence to TB treatment}

Overall, 197 (64.2\%) of the participants were adherent (95\% CI 58.6-69.4\%) to TB treatment during continuation phase. The finding showed that 65 (34.8\%) of pulmonary TB and 45 (37.5\%) of extra pulmonary TB cases were adherent to TB treatment during continuation phase. One hundred three (35.9\%) new and 7 $(35.0 \%)$ repeated treatment cases were adherent to TB treatment (Table 2).

Focal TB healthcare providers were asked about "which treatment phase has a higher risk of nonadherence to the treatment?" Five of nine focal healthcare providers agreed that non-adherence to TB treatment worsens during the continuation phase as compared with the intensive phase, where patients take their daily pills at the clinic directly observed by the healthcare provider. One male TB focal healthcare provider replied that:

"... when patients enrolled in the continuation phase, they often get reluctant to their pills. Let alone daily medication, they even miss weekly refilling appointments, however, during the intensive phase, they come to take their pills on time"

\section{Determinants of adherence to TB treatment during continuation phase}

The univariate logistic regression analysis showed that patient age, educational level, distance to the health facility, provider-patient relationship, patient knowledge on TB treatment, and family wealth index were associated with adherence to $\mathrm{TB}$ treatment during the continuation phase.

Whereas, in the multivariable binary logistic regression analysis, patients' educational level, providerpatient relationship, patient knowledge on TB treatment, and family wealth index were associated with the outcome variable. Secondary level educated patients were about four times more likely to adhere to TB treatment as compared to non-educated patients (AOR $=4.138,95 \%$ CI; 1.594-10.740). Similarly, patients who reported good provider-patient relationships were about two times more likely to adhere to the treatment than their counterparts, with (AOR = 1.863, 95\% CI; 1.014-3.423). Those who have good knowledge of TB treatment were also more likely to adhere $(\mathrm{AOR}=1.845,95 \% \mathrm{CI} ; 1.012-3.362)$. Patients with middle family wealth were about three times more likely to adhere than patients with poor family wealth $(\mathrm{AOR}=2.646,95 \% \mathrm{CI} ; 1.360-5.148)$ (Table 3$)$.

Patients who were non-adherent to their TB medication were asked for their reasons for failure to treatment adherence. More than half (58\%) of 110 non-adherent participants reported forgetfulness to daily medication, $17.3 \%$ reported traveling away from home without pills, 8.2 and $5.5 \%$ were due to feeling sick and fearing side effects of the drugs, respectively (Fig. 1). 
Table 1 Socio-demographic characteristics of participants, northwest Ethiopia $(n=307)$

\section{Characteristics}

Age

$$
\begin{aligned}
& \text { Below } 25 \\
& 25-34 \\
& 35-44 \\
& 45+
\end{aligned}
$$

84 (27.4)

$110(35.8)$

$60(19.5)$

53 (17.3)

Sex

Male

$178(58.0)$

Female

$129(42.0)$

Marital status

Single

Married

119 (38.8)

Divorced

$34(11.1)$

Widowed

$12(3.9)$

Religion

Orthodox

$285(92.8)$

Muslim

$20(6.5)$

Others

$2(.7)$

Residence

Urban

$220(71.7)$

Rural

87 (28.3)

Educational level

Can't read and write

$101(32.9)$

Informally educated

37 (12.1)

Primary

73 (23.8)

Secondary

56 (18.2)

Higher

$40(13.0)$

Partner's educational level

Can't read and write

47 (39.5)

Informally educated

$10(8.4)$

Primary

$33(27.7)$

Secondary

17 (14.3)

Higher

Type of facility enrolled for treatment

Health Center

267 (86.9)

Hospital

40 (13.1)

Family wealth quantile

Lowest

$62(20.2)$

Second

61 (19.9)

Middle

$62(20.2)$

Fourth

61 (19.9)

Highest 
Table 1 Socio-demographic characteristics of participants, northwest Ethiopia $(n=307)$ (Continued)

\begin{tabular}{lr}
\hline Characteristics & n (\%) \\
\hline Own a mobile phone & $55(17.9)$ \\
Yes, smartphone & $130(42.4)$ \\
Yes, basic phone & $122(39.7)$ \\
Not at all & 122 \\
\hline
\end{tabular}

TB focal healthcare providers were also asked for their perspectives about contributing factors for nonadherence to TB treatment. Poor communication and relationship with their patients, transportation and related costs for pill refilling, relapsing of the disease, political unrest, and poor treatment support at the community were found major contributing factors for non-adherence to TB treatment during the continuation phase.

All respondents agreed that good communication and relationship was essential for patient adherence to TB medications. However, about half (4/9) of participants reported that their communication with patients declined as the patients shifted from the intensive phase (facility-based treatment) to the continuation phase. Another male TB focal healthcare provider also added that:

"During the continuation phase, we do not have daily contact with patients as we do on intensive phase. Even, weekly attendance was not easy. Some patients did not come, they send their supporter/

Table 2 Adherent to TB treatment by clinical characteristics of participants during continuation phase, northwest Ethiopia ( $n=$ 307)

\begin{tabular}{|c|c|c|}
\hline \multirow[t]{2}{*}{ Characteristics } & \multicolumn{2}{|c|}{ Adherent to TB treatment } \\
\hline & Yes & No \\
\hline \multicolumn{3}{|l|}{ Type of TB } \\
\hline Pulmonary TB & $122(65.2 \%)$ & $65(34.8 \%)$ \\
\hline Extra pulmonary TB & $75(62.5 \%)$ & 45 (37.5\%) \\
\hline \multicolumn{3}{|l|}{ Treatment category } \\
\hline New & $184(64.1 \%)$ & $103(35.9 \%)$ \\
\hline Relapse & $13(65.0 \%)$ & $7(35.0 \%)$ \\
\hline \multicolumn{3}{|c|}{ Disclosed TB status to family } \\
\hline Yes & 189 (64.3\%) & $105(35.7 \%)$ \\
\hline No & $8(61.5 \%)$ & $5(38.5)$ \\
\hline \multicolumn{3}{|l|}{ TB/HIV co-infected } \\
\hline Yes & $14(53.9 \%)$ & $12(46.2 \%)$ \\
\hline No & $183(65.1 \%)$ & 98 (34.9\%) \\
\hline Overall adherence & 197 (64.2\%) & $110(33.3)$ \\
\hline
\end{tabular}

family member to the clinic for refilling, and they were busy with family matters, social events like a funeral."

In the key-informant interview, the majority of TB focal providers also exemplified that patients with low income tend to miss and/or interrupt refilling due to transportation and related costs. Besides, relapse cases tend to default treatments. A female TB focal healthcare provider replied that

"TB patients on continuation phase often miss refilling and from my experience, their reasons are mainly related to transportation cost and unintended social events".

Participants also mentioned that relapsing cases tend to lost-to-follow-up. Another female focal healthcare provider added that:

"This year alone we lost two patients due to relapse of the case [TB]. One female insisted not to take the pills anymore and decided to go to Monastery. Similarly, one male patient lost from treatment followup ..."

Political unrest and security problems were among the challenges for the patient, the health facility, and central drug suppliers (hubs for supplying drugs based on the health facilities' need). A male TB focal healthcare provider replied that

"Our community was victimized with frequent political turmoil and security problems which results in lost-to-follow due to massive displacement, migration of healthcare providers, and interruption of drug supply from the center."

Respondents were also asked their opinion on whether the assigned treatment supporters were helpful during the continuation treatment phase. Seven of nine participants replied that they were not helpful as intended, and $(2 / 9)$ reported as helpful. The problem begins with assigning treatment supporters. A male TB focal healthcare provider reported that: 
Table 3 Factors associated with adherence to TB medication and pill refilling during continuation phase in Northwest Ethiopia $(n=$ 307)

\begin{tabular}{|c|c|c|c|c|}
\hline \multirow[t]{2}{*}{ Variables } & \multicolumn{2}{|c|}{ Adherent } & \multirow[t]{2}{*}{$\operatorname{COR}(95 \% \mathrm{Cl})$} & \multirow[t]{2}{*}{ AOR(95\%Cl) } \\
\hline & Yes & No & & \\
\hline \multicolumn{5}{|l|}{ Patient age } \\
\hline 24 years and below & 58 & 26 & $2.317(1.139-4.712)^{*}$ & $1.533(.642-3.661)$ \\
\hline $25-34$ years & 81 & 29 & $2.901(1.461-5.757)^{*}$ & $2.123(.937-4.813)$ \\
\hline $35-44$ years & 32 & 28 & $1.187(.566-2.487)$ & $.879(.378-2.043)$ \\
\hline $45+$ years & 26 & 27 & 1 & 1 \\
\hline \multicolumn{5}{|l|}{ Sex } \\
\hline Male & 113 & 65 & 1 & 1 \\
\hline Female & 84 & 45 & $1.074(.669-1.724)$ & $1.251(.707-2.214)$ \\
\hline \multicolumn{5}{|l|}{ Residence } \\
\hline Urban & 146 & 74 & $1.393(.836-2.320)$ & $.764(.374-1.559)$ \\
\hline Rural & 51 & 36 & 1 & 1 \\
\hline \multicolumn{5}{|l|}{ Educational level } \\
\hline No education & 53 & 48 & 1 & 1 \\
\hline Informal education & 20 & 17 & $1.065(.501-2.268)$ & $.729(.299-1.773)$ \\
\hline Primary & 45 & 28 & $1.456(.789-2.685)$ & $1.057(.501-2.231)$ \\
\hline Secondary & 46 & 10 & $4.166(1.895-9.157)^{*}$ & $4.138(1.594-10.74)^{*}$ \\
\hline Higher & 33 & 7 & $4.27(1.728-10.55)^{*}$ & $2.795(.970-8.052)$ \\
\hline \multicolumn{5}{|c|}{ Distance to the health facility } \\
\hline Less than $5 \mathrm{~km}$ & 72 & 156 & $2.708(1.206-6.081)^{*}$ & $2.275(.877-5.903)$ \\
\hline $5-10 \mathrm{~km}$ & 23 & 29 & $1.576(.618-4.018)^{*}$ & $1.672(.589-4.746)$ \\
\hline Greater than $10 \mathrm{~km}$ & 15 & 12 & 1 & 1 \\
\hline \multicolumn{5}{|c|}{ Treatment supporter assigned } \\
\hline Yes & 74 & 123 & 1 & 1 \\
\hline No & 36 & 73 & $1.22(.746-1.996)$ & $1.375(.769-2.457)$ \\
\hline \multicolumn{5}{|c|}{ Disclosed TB status to family } \\
\hline Yes & 105 & 189 & $1.125(.359-3.527)$ & $.744(.191-2.902)$ \\
\hline No & 5 & 8 & 1 & 1 \\
\hline \multicolumn{5}{|c|}{ Provider-patient relationship } \\
\hline Good & 112 & 45 & $1.903(1.186-3.055)^{*}$ & $1.863(1.014-3.423)^{*}$ \\
\hline Poor & 85 & 65 & 1 & 1 \\
\hline \multicolumn{5}{|c|}{ Knowledge on TB treatment } \\
\hline Good & 157 & 72 & $2.072(1.226-3.5)^{*}$ & $1.845(1.012-3.362)^{*}$ \\
\hline Poor & 40 & 38 & 1 & 1 \\
\hline \multicolumn{5}{|c|}{ Attitude on TB treatment } \\
\hline Favorable & 121 & 59 & $1.376(.858-2.206)$ & $1.272(.702-2.305)$ \\
\hline Unfavorable & 76 & 51 & 1 & \\
\hline \multicolumn{5}{|l|}{ Family wealth index } \\
\hline Poor & 54 & 49 & 1 & 1 \\
\hline Middle & 71 & 31 & $2.078(1.173-3.683)^{*}$ & $2.646(1.360-5.148)^{*}$ \\
\hline Rich & 72 & 30 & $2.178(1.225-3.871)^{*}$ & $1.949(.957-3.968)$ \\
\hline
\end{tabular}

${ }^{*} p$-value less than 0.05 


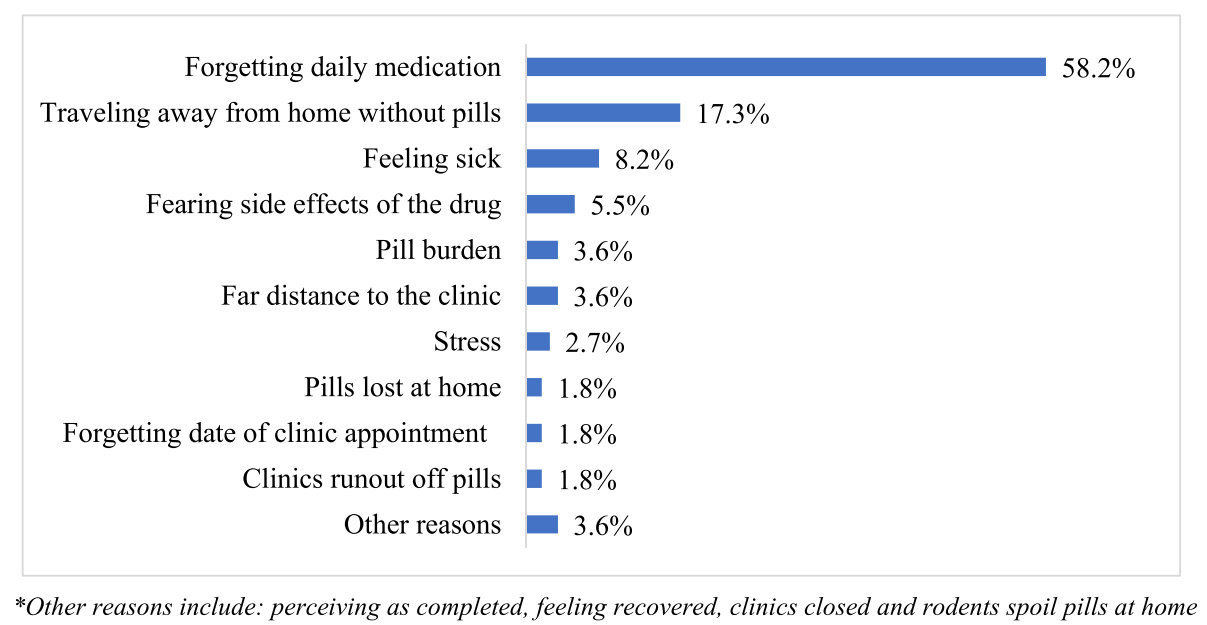

Fig. 1 Patients' reasons for non-adherence to TB treatment during continuation phase $(n=110)$. ${ }^{*}$ Other reasons include: perceiving as completed, feeling recovered, clinics closed and rodents spoil pills at home

"During assigning treatment supporters, patients often choose educated relatives without considering the distance away from their home: mostly, they choose their relatives in urban while the patient living in rural."

In addition, the commitment of treatment supporters was confronted by their income level and their prior commitments as reported by the respondents. A male TB focal healthcare provider mentioned that:

"Treatment supporters very rarely accompany patients during refilling, they mention transportation cost, own family, and social commitments."

Another male TB focal healthcare provider also added that:

"During the continuation phase, we assign treatment supporters but in practice, most did not follow and most focal providers lack skills to influence patients to take their pills at home"

\section{Discussion}

This study identified that adherence to TB treatment was low among adult TB patients during continuation phase in northwest Ethiopia. Patients' educational level, knowledge, family wealth, and provider-patient relationship were positively associated with adherence to TB treatment. From the healthcare providers' perspectives, poor communication and relationship with patients, transportation and related costs for refilling, relapsing of the disease, political unrest, and poor treatment support at the community were major underlying factors for non-adherence to TB treatment during the continuation phase.

The finding was similar with a study done in Gondar town of northwest Ethiopia [19]. Whereas, the finding was lower as compared to the pooled estimate of the national level of adherence to TB treatment [16]. Similarly, It was also lower as compared with other studies conducted in different parts of Ethiopia including in Arba Minch town [14], in Sidama [35], in Addis Ababa [15], in Alamata [12]. The discrepancy could be due to the current study included patients only from the continuation phase and other studies involved both intensive and continuation phases. And evidences indicated that non-adherence to TB treatment worsens during the continuation phase $[18,19,27]$. In this study, TB focal healthcare providers also have shown their agreement that the continuation phase was a risk for patients' failure to adhere to TB treatment. Besides, we used a composite items to measure adherence to $\mathrm{TB}$ treatment. While, previous studies used pill count as a measure of adherence that often distorted the problem [26].

This study has shown that educational level was positively associated with adherence to TB treatment. The finding was in line with a study conducted in Equatorial Guinea [36] and Nepal [37] indicated that patient literacy was a significant factor for non-adherence to TB treatment. The current study has shown that patients with the middle family wealth index were about 3 times more likely to adhere to their TB medication as compared to patients in poor family wealth index. Patients with rich family wealth have also shown higher adherence as compared to patients in the poor category, however, it was marginally insignificant. The finding was in line with a study in Nepal [37]. Our qualitative finding also supported that transportation and related expenses 
during traveling for pill refilling were among the challenges that directly influence their adherence to the treatment.

Similarly, a good provider-patient relationship was also significantly associated with patient adherence during the continuation phase. The finding was consistent with previous studies which reported that provider-patient relationship was associated with adherence to TB treatment in Ethiopia [19-21]. Our qualitative analysis also revealed that healthcare providers did not have a strong relationship with their patients. Provider-patient relationship is considered as the core element of ethical principles of medicine that establish trust and motivation to engage patients on their treatment. The relationship could be a driver of good clinical outcomes. It promotes desired treatment results and also prevents adverse treatment outcomes [38, 39].

Patients with good knowledge related to TB treatment were about 2 times more likely to adhere to their medication and refilling. Similarly, studies in Ethiopia [17, 19] and China [30] also reported that poor knowledge about TB and TB treatment was significantly associated with non-adherence.

Generally, this study has shown that non-adherence to TB treatment was a problem during the continuation phase in the area. It implies that the level of adherence is different across treatment phases that could require to establish tailored strategies specific to continuation phases to improve patient adherence to TB treatment.

\section{Limitation of the study}

This study specifically focused on continuation treatment phase that could give insight for policy, program and delivery of TB treatment and care. The limitation of the study includes use of self-reported adherence that often distort the problem due to recall and social desirability biases. Our study participants were enrolled from public health centres and hospitals. We did not address patients at private health facilities and health post levels. This could affect the generalizability of the study findings to the wider context. The ARMS tool looks to have very strict criteria in classifying adherence level. As a result, the level of adherence could be underestimated. We did not address all possible predictors of adherence to TB treatment during continuation phase. ARMS tool do not allow to classify adherence at data collection stage, it classifies after data analysis. Therefore, we asked about patient reasons for non-adherence to $\mathrm{TB}$ medication based on those missed one or more doses.

\section{Conclusion}

TB treatment adherence was low during the continuation phase in northwest Ethiopia. Patients' educational level, family wealth, provider-patient relationship, and patient knowledge related to $\mathrm{TB}$ treatment were positively associated with the level of adherence. Traditional and innovative interventional strategies would be useful to facilitate provider-patient relationships and TB treatment related knowledge of patients to improve their adherence to TB treatment during the continuation phase.

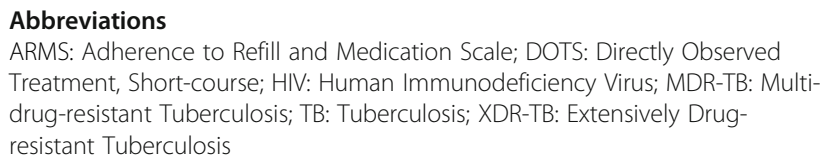

\section{Acknowledgments}

We would like to acknowledge the SEARCH (NORPART) project for facilitating student exchange for sharing research experiences at the University of Oslo. The authors are grateful to DDCF for covering the data collection cost of this study. We are also grateful to data collectors and TB focal healthcare providers for their dedication to data collection and facilitation.

\section{Authors' contributions}

KDG, BT and KAG have initiated the study concept. KDG, BT and KAG made a substantial contribution to the design and data analysis. KDG contributed in the write-up of the manuscript. All authors read and approved the manuscript.

\section{Funding}

This research received no specific grant from any funding agency in the public, commercial or not-for-profit sectors.

\section{Availability of data and materials}

The datasets used and/or analysed during the current study are available from the corresponding author on reasonable request.

\section{Declarations}

Ethics approval and consent to participate

Ethical clearance was obtained from the Institutional Review Board (IRB) of the University of Gondar with an approval number ON/P/RCS/05/1077/2018. Participants have signed to the written informed consent form after discussing with participants' rights and responsibilities, possible harms, and benefits of participating in the study. Key-informants were informed about audio recording before signing the consent form. The study did not use personal identifiers during data collection, storage, and dissemination.

\section{Consent for publication}

Not applicable.

\section{Competing interests}

The authors declared that there is no competing interest.

\section{Author details}

${ }^{1}$ Department of Health Informatics, Institute of Public Health, College of Medicine and Health Sciences, University of Gondar, Gondar, Ethiopia. ${ }^{2}$ Department of Epidemiology and Biostatistics, Institute of Public Health, College of Medicine and Health Sciences, University of Gondar, Gondar, Ethiopia.

Received: 1 January 2021 Accepted: 12 July 2021

Published online: 31 July 2021

References

1. WHO Tuberculosis Programme. framework for effective tuberculosis control, 1994. World Health Organization. https://apps.who.int/iris/handle/10665/ 58717 [Accessed 29 Aug 2019].

2. Fox W, Ellard GA, Mitchison DA. Studies on the treatment of tuberculosis undertaken by the British Medical Research Council tuberculosis units, 19461986, with relevant subsequent publications. Int J Tuberc Lung Dis. 1999; 3(10 Suppl 2):S231-79. 
3. World Health Organization. Stop TB Dept., World Health Organization. Dept. of HIV/AIDS. Interim policy on collaborative TB/HIV activities. Geneva: World Health Organization; 2004. p. 19.

4. Karumbi J, Garner P. Directly observed therapy for treating tuberculosis. Cochrane Database Syst Rev. 2015;2015(5):CD003343. https://doi.org/10.1 002/14651858.CD003343.pub4.

5. M'imunya JM, Kredo T, Volmink J. Patient education and counselling for promoting adherence to treatment for tuberculosis. Cochrane Database Syst Rev. 2012;2012(5):CD006591. https://doi.org/10.1002/14651858. CD006591.pub2

6. Liu Q, Abba K, Alejandria MM, Sinclair D, Balanag VM, Lansang MA. Reminder systems to improve patient adherence to tuberculosis clinic appointments for diagnosis and treatment. Cochrane Database Syst Rev. 2014;2014(11):CD006594. https://doi.org/10.1002/14651858.CD006594.pub3.

7. WHO. Global tuberculosis report. 2016 https:/apps.who.int/medicinedocs/ en/d/Js23098en/. Accessed 27 Aug 2019.

8. WHO. Adherence to long-term therapies: evidence for action. 2003.

9. Alemu A, Bitew ZW, Worku T. Poor treatment outcome and its predictors among drug-resistant tuberculosis patients in Ethiopia: a systematic review and meta-analysis. Int J Infect Dis. 2020;98:420-39. https://doi.org/10.1016/j. ijid.2020.05.087.

10. Seid MA, Ayalew MB, Muche EA, Gebreyohannes EA, Abegaz TM. Drugsusceptible tuberculosis treatment success and associated factors in Ethiopia from 2005 to 2017: a systematic review and meta-analysis. BMJ Open. 2018;8(9):e022111. https://doi.org/10.1136/bmjopen-2018-022111.

11. Eshetie S, Gizachew M, Alebel A, van Soolingen D. Tuberculosis treatment outcomes in Ethiopia from 2003 to 2016, and impact of HIV co-infection and prior drug exposure: a systematic review and meta-analysis. PLoS One. 2018;13(3):e0194675. https://doi.org/10.1371/journal.pone.0194675.

12. Tesfahuneygn $\mathrm{G}$, Medhin $\mathrm{G}$, Legesse M. Adherence to anti-tuberculosis treatment and treatment outcomes among tuberculosis patients in Alamata District, Northeast Ethiopia. BMC research notes. 2015;8(1):503. https://doi. org/10.1186/s13104-015-1452-x.

13. Kahissay $\mathrm{MH}$. Assessment of Patient Adherence to Tuberculosis Treatment in Dessie Referral Hospital, South Wollo, Ethiopia, doi:https://doi.org/10.7910/ DVN/QSGPA0. Harvard Dataverse. 2016;V1.

14. Gube AA, Debalkie M, Seid K, et al. Assessment of anti-TB drug nonadherence and associated factors among TB patients attending TB clinics in Arba Minch governmental health institutions, Southern Ethiopia. Tuberc Res Treatment. 2018;2018:3705812.

15. Tola HH, Shojaeizadeh D, Tol A, Garmaroudi G, Yekaninejad MS, Kebede A, et al. Psychological and educational intervention to improve tuberculosis treatment adherence in Ethiopia based on health belief model: a cluster randomized control trial. PLoS One. 2016;11(5):e0155147. https://doi.org/1 0.1371/journal.pone.0155147.

16. Zegeye A, Dessie G, Wagnew F, et al. Prevalence and determinants of antituberculosis treatment non-adherence in Ethiopia: A systematic review and meta-analysis. PloS one. 2019;14(1):e0210422-e.

17. Woimo TT, Yimer WK, Bati T, Gesesew HA. The prevalence and factors associated for anti-tuberculosis treatment non-adherence among pulmonary tuberculosis patients in public health care facilities in South Ethiopia: a cross-sectional study. BMC Public Health. 2017;17(1):269. https:// doi.org/10.1186/s12889-017-4188-9.

18. Adane AA, Alene KA, Koye DN, Zeleke BM. Non-adherence to antituberculosis treatment and determinant factors among patients with tuberculosis in Northwest Ethiopia. PLoS One. 2013;8(11):e78791. https://doi. org/10.1371/journal.pone.0078791.

19. Mekonnen HS, Azagew AW. Non-adherence to anti-tuberculosis treatment, reasons and associated factors among TB patients attending at Gondar town health centers, Northwest Ethiopia. BMC Res Notes. 2018;11(1):691.

20. Gugssa Boru C, Shimels T, Bilal Al. Factors contributing to non-adherence with treatment among TB patients in Sodo Woreda, Gurage zone, southern Ethiopia: a qualitative study. J Infect Public Health. 2017;10(5):527-33. https://doi.org/10.1016/j.jiph.2016.11.018.

21. Tola HH, Tol A, Shojaeizadeh D, Garmaroudi G. Tuberculosis treatment nonadherence and lost to follow up among TB patients with or without HIV in developing countries: a systematic review. Iran J Public Health. 2015;44(1):111.

22. Martin C, Perfect T, Mantle G. Non-attendance in primary care: the views of patients and practices on its causes, impact and solutions. Fam Pract. 2005; 22(2):38-43.
23. Neal RD, Hussain-Gambles M, Allgar VL, et al. Reasons for and consequences of missed appointments in general practice in the UK: questionnaire survey and prospective review of medical records. BMC Fam Pract. 2005;47:6. https://doi.org/10.1186/1471-2296-6-47.

24. van Baar JD, Joosten H, Car J, Freeman GK, Partridge MR, van Weel C, et al. Understanding reasons for asthma outpatient (non)-attendance and exploring the role of telephone and e-Consulting in Facilitating Access to care: exploratory qualitative study. Qual Saf Health Care. 2006;15(3):191-5. https://doi.org/10.1136/qshc.2004.013342.

25. Crosby LE, Modi AC, Lemanek KL, Guilfoyle SM, Kalinyak KA, Mitchell MJ. Perceived barriers to clinic appointments for adolescents with sickle cell disease. J Pediatr Hematol Oncol. 2009;31(8):571-6. https://doi.org/10.1097/ MPH.0b013e3181acd889.

26. Vrijens B, Urquhart J, White D. Electronically monitored dosing histories can be used to develop a medication-taking habit and manage patient adherence. Expert Rev Clin Pharmacol. 2014;7(5):633-44. https://doi.org/10.1 586/17512433.2014.940896

27. Fiseha D, Demissie M. Assessment of directly observed therapy (DOT) following tuberculosis regimen change in Addis Ababa, Ethiopia: a qualitative study. BMC Infect Dis. 2015;15(1):405. https://doi.org/10.1186/s12 879-015-1142-2.

28. Nunnally J, Bernstein IH. Psychometric theory. 3rd ed. New York: McGrawHill; 1994

29. Kulkarni P, Akarte S, Mankeshwar R, Bhawalkar JS, Banerjee A, Kulkarni AD. Non-adherence of new pulmonary tuberculosis patients to anti-tuberculosis treatment. Ann Med Health Sci Res. 2013;3(1):67-74. https://doi.org/10.41 03/2141-9248.109507.

30. Tang $Y$, Zhao M, Wang $Y$, et al. Non-adherence to anti-tuberculosis treatment among internal migrants with pulmonary tuberculosis in Shenzhen, China: a cross-sectional study. BMC Public Health. 2015;15:474.

31. Rutstein SO. The DHS wealth index: Approaches for rural and urban areas. Calverton: Macro International; 2008.

32. Mayberry LS, Gonzalez JS, Wallston KA, Kripalani S, Osborn CY. The ARMS-D out performs the SDSCA, but both are reliable, valid, and predict glycemic control. Diabetes Res Clin Pract. 2013;102(2):96-104. https://doi.org/10.1016/ j.diabres.2013.09.010.

33. Kripalani S, Risser J, Gatti ME, et al. Development and evaluation of the adherence to Refillls and medications scale (ARMS) among low-literacy patients with chronic disease. Value Health. 2009;12(1):118-23. https://doi. org/10.1111/j.1524-4733.2008.00400.x.

34. Akinwande $M$, Dikko $H$, Samson A. Variance inflation factor: as a condition for the inclusion of suppressor variable(s) in regression analysis. Open J Stat. 2015;5(07):754-67. https://doi.org/10.4236/ojs.2015.57075.

35. Nezenega ZS, Gacho YH, Tafere TE. Patient satisfaction on tuberculosis treatment service and adherence to treatment in public health facilities of Sidama zone, South Ethiopia. BMC Health Serv Res. 2013;13(1):110. https:// doi.org/10.1186/1472-6963-13-110.

36. Fagundez G, Perez-Freixo H, Eyene J, Momo JC, Biyé L, Esono T, et al. Treatment adherence of tuberculosis patients attending two reference units in Equatorial Guinea. PLoS One. 2016;11(9):e0161995. https://doi.org/10.13 71/journal.pone.0161995.

37. Mishra P, Hansen EH, Sabroe S, et al. Socio-economic status and adherence to tuberculosis treatment: a case-control study in a district of Nepal. Int J Tuberc Lung Dis. 2005;9(10):1134-9.

38. Chipidza FE, Wallwork RS, Stern TA. Impact of the Doctor-Patient Relationship. Prim Care Companion CNS Disord. 2015;17(5). https://doi.org/1 0.4088/PCC.15f01840.

39. Gordon C, Phillips M, Beresin EV. 3 - the doctor-patient relationship. In: Stern TA, Fricchione GL, Cassem NH, Jellinek MS, Rosenbaum JF, editors. Massachusetts General Hospital handbook of general hospital psychiatry. 6th ed. Saint Louis: W.B. Saunders; 2010. p. 15-23. https://doi.org/10.1016/ B978-1-4377-1927-7.00003-0.

\section{Publisher's Note}

Springer Nature remains neutral with regard to jurisdictional claims in published maps and institutional affiliations. 